\title{
Desafios e métodos na gestão da empresa familiar
}

\author{
Challenges and methods in managing the family business \\ Desafíos y métodos en la gestión de la empresa familiar
}

Recebido: 27/01/2022 | Revisado: 03/02/2022 | Aceito: 05/02/2022 | Publicado: 09/02/2022

\author{
Thiago Silva Brito \\ ORCID: https://orcid.org/0000-0002-1345-8278 \\ Universidade Estadual de Minas Gerais, Brasil \\ E-mail: thgbrito@hotmail.com \\ Jhonata Ongaratto \\ ORCID: https://orcid.org/0000-0001-5143-611X \\ Universidade Estadual de Minas Gerais, Brasil \\ E-mail: jhoon_ongaratto@hotmail.com \\ Miriam Pinheiro Bueno \\ ORCID: https://orcid.org/0000-0002-3961-7396 \\ Universidade Estadual de Minas Gerais, Brasil \\ E-mail: miriam.bueno@umeg.br
}

\begin{abstract}
Resumo
As empresas familiares possuem elevada importância no desenvolvimento da economia, pois representam uma parte significativa do PIB (produto interno bruto) e são responsáveis por gerar milhões de empregos no mundo. A gestão de todas as empresas apresenta alguns objetivos em comum, porém as empresas de origem familiar apresentam certas peculiaridades devido aos seus vínculos. O objetivo foi apresentar aspectos importantes na gestão de empresas familiares, abordando temas que poderiam representar desafios em sua gestão e propor métodos para sua resolução. Utilizou-se os processos metodológicos qualitativo, exploratório, descritivo e bibliográfico. Foram avaliados na literatura o processo sucessório, a importância da tradição e valores da família e a tomada de decisão. Os resultados apontam que o processo sucessório eficiente depende de planejamento e profissionalização do sucessor. Concluiu-se que há métodos eficazes estabelecidos para auxiliar a tomada de decisão de empresas familiares de forma a minimizar a influência de conflitos de interesse da família. E o presente trabalho também ressalta a importância de preservar os valores da organização familiar.
\end{abstract}

Palavras-chave: Empresa familiar; Gestão empresarial; Processo sucessório.

\begin{abstract}
Family businesses have a high importance in the development of the economy, since they represent a significant part of the GDP (gross domestic product) and are responsible for generating millions of jobs worldwide. The management of all companies has some common purposes, but family-owned companies have certain peculiarities due to their close ties. The objective was to present important aspects in the management of family businesses, approaching subjects that could represent challenges in their management and proposing methods for their resolution. The methodological processes used were qualitative, exploratory, descriptive, and bibliographic. The succession process, the importance of tradition and family's values, and decision making were evaluated in the literature. The results indicate that an efficient succession process depends on the successor's planning and professionalization. It was concluded that there are effective methods established to support the decision making of family businesses in order to minimize the influence of conflicts of interest of the family. And the present work also highlights the importance of preserving the values of the family organization.
\end{abstract}

Keywords: Family business; Business management; Succession process.

\section{Resumen}

Las empresas familiares son muy importantes para el desarrollo de la economía, ya que representan una parte zsignificativa del PIB (producto interior bruto) y son responsables de generar millones de puestos de trabajo en todo el mundo. La gestión de todas las empresas presenta algunos objetivos en común, sin embargo, las empresas familiares tienen ciertas peculiaridades debido a sus vínculos. El objetivo fue exponer aspectos importantes en la gestión de las empresas familiares, abordando cuestiones que podrían representar desafíos en su gestión y proponer métodos para su resolución. Se utilizaron procesos metodológicos cualitativos, exploratorios, descriptivos y bibliográficos. El proceso de sucesión, la importancia de la tradición y los valores de familia y la toma de decisiones fueron evaluados en la literatura. Los resultados señalan que la eficacia del proceso de sucesión depende de la planificación y la profesionalización del sucesor. Se llegó a la conclusión de que existen métodos eficaces establecidos para ayudar a la 
toma de decisiones de las empresas familiares con el fin de minimizar la influência de los conflictos de intereses de la familia. Y el presente trabajo también destaca la importancia de preservar los valores de la organización familiar.

Palabras clave: Empresa familiar; Gestión empresarial; Proceso de sucesión.

\section{Introdução}

A definição de empresa familiar é abrangente e diversificada entre autores. No geral é denominada como familiar a organização que possuem ações de uma empresa administradas por uma linhagem (Mamede et al.,2017). Um dos conceitos mais antigos é proposto por Donnelley (1967), no qual sugere que para uma organização ser considerada familiar é preciso que sua existência esteja associada a uma família por no mínimo duas gerações e estes vínculos tenham influência sobre as diretrizes e objetivos da empresa (Albuquerque Filho et al., 2019).

As empresas familiares são de suma importância no desenvolvimento do país, representando parcelas significativas do produto interno bruto (PIB) mundial e grande parte do número total de empresas. Segundo dados relatados pelo Serviço Brasileiro de Apoio às Micro e Pequenas Empresas (SEBRAE, 2021a) cerca de 90\% das empresas do Brasil são de origem familiar e, portanto, são responsáveis por cerca de $65 \%$ do produto interno bruto (PIB) e empregabilidade de quase $75 \%$ dos trabalhadores.

Empresas familiares podem apresentar dinâmicas diferentes das demais, devido a fatores como a influência dos interesses da família, os vínculos afetivos, os valores, tradições e a busca por uma continuidade da empresa incentivado não somente pelo lucro, mas também pela preservação de sua história. É válido salientar que estas instituições buscam a longevidade nos negócios vinculados a hereditariedade e preocupam-se com a gestão das emoções do relacionamento familiar, ambicionando não só ampliar a riqueza da empresa, mas também dar continuidade a ela através da sucessão (Santos et al., 2018).

Uma classificação destas organizações foi proposta pelo Serviço Brasileiro de Apoio às Micro e Pequenas Empresas (SEBRAE, 2021b), separando-as em 3 grupos: empresa de controle familiar (a família detém o controle da empresa com aproximadamente $51 \%$ ou mais das cotas ou ações); empresa de administração familiar (membros da família exercem a administração da empresa, especialmente nos cargos mais elevados, porém, é possível que a família não tenha o controle da empresa, não detendo as cotas e ações majoritárias que pertencem a outros proprietários); empresa familiar tradicional (a família é responsável tanto pelo controle como pela administração dos negócios).

Como características positivas na gestão de empresas familiares pode-se citar os interesses mútuos, a confiança entre os membros, a autoridade bem estabelecida, compatibilidade de valores e tradições (Frezarin et. al, 2021). Também, são importantes a propensão dos parentes em investir o próprio capital ou oferecer garantias quando for necessário levantar recursos (Adachi, 2006). Em contrapartida, grande parte das empresas familiares não sobrevivem à terceira geração, por isso é necessário desenvolver estratégias eficientes para a continuidade dos negócios. Como elementos negativos pode-se citar: conflitos de interesses entre família e empresa; dificuldade de administrar o capital, com usos indevidos deste para interesses particulares; resistência à modernização; e emprego e promoções de parentes por favoritismo e critérios subjetivos, especialmente em cargos mais elevados que são reservados a parentes (Adachi, 2006). Portanto, o trabalho levanta indagações: quais os elementos importantes na gestão de empresas familiares? Quais os desafios em sua gestão? Existem métodos para sua resolução dos desafios?

Os questionamentos se justificam, pois, apesar da gestão das empresas apresentarem algumas similaridades nas questões a serem consideradas no planeamento, a gestão em empresas familiares pode apresentar problemas específicos e abordagens diferentes para a resolução. Essa gestão é influenciada por características peculiares que podem gerar problemas à 
medida que surgem conflitos de interesses, visões e opiniões divergentes dentro da família (Guerini et al., 2018). O equilíbrio entre a gestão dos negócios e da família é o maior desafio encontrado nessas empresas.

A gestão de uma empresa é determinada por processos relacionados a planificação, organização, liderança e controlo das atividades. Na planificação os principais responsáveis definem objetivos e sugerem estratégias para alcança-los. A organização determina a forma de distribuir a autoridade, o trabalho e os recursos aos funcionários da empresa para que possam atingir os objetivos, realizando, portanto, uma definição estrutural da empresa. A liderança delimita como são dirigidos e motivados os trabalhadores no desenvolvimento do seu trabalho. É por meio da função de controle que os gestores conseguem manter coerentes os objetivos nas diversas áreas que constituem a empresa, de modo a manter o foco nos objetivos anteriormente definidos (Lisboa et al., 2004). Portanto, é necessário avaliar os fatores na gestão das empresas familiares que podem acarretar desvantagens nos negócios frente a outros tipos de organização e propor, dessa forma métodos para melhorar os fluxos dos processos internos destas.

Em seu estudo Schreiber et al., () constataram que fatores como o processo decisório organizacional, concepção estratégica e a presença de um líder como formador de opinião são importantes durante o posicionamento estratégico em empresas familiares para competir com as demais do mercado. Já em sua avaliação sobre o fechamento da empresa Guerra SA, Buchweitz et al. (2019) evidenciaram que a morte do fundador da empresa e o afastamento da família da gestão contribuíram para a perda da riqueza sociemocional da empresa, e esses elementos somados aos tomadores de decisão não atuarem com eficácia e união contribuíram com o declínio da organização. Um estudo de Piccoli et al. (2019) mostrou que conflitos de interesse, desinteresse de herdeiros e resistência dos gestores em fazer a sucessão podem atrapalhar o processo sucessório e que mesmo microempresas tendem a contratar consultores para realizar o planejamento de uma sucessão efetiva para gerir a empresa depois da saída de seus fundadores. Dessa forma, é perceptível a importância de questões como a tomada de decisão, a presença dos valores da família e o processo sucessório bem estabelecido para que a empresa possa competir no mercado, de desenvolver economicamente e ter continuidade ao longo das gerações.

O objetivo deste estudo é apresentar tópicos importantes na gestão de empresas familiares, abordando problemas inerentes a este tipo de organização que possam impactar no seu desenvolvimento econômico, na continuidade ao longo das gerações e propor sugestões para definir estratégias de gestão mais eficientes. O presente trabalho expõe nos desafios e problemas que precisam ser avaliados no planejamento da empresa. Devido as suas relações singulares, serão abordados temas com interferências diretas da família na administração dos negócios, sendo estes o processo sucessório, a tomada de decisão e a importância dos valores e tradições no ambiente empresarial.

O trabalho está estruturado nas seções de: Fundamentação Teórica, abordando os conceitos de empresa familiar e questões a serem considerados na gestão (processo sucessório, a importância da tradição e valores em empresas familiares e a tomada de decisão), resultados com levantamento dos temas abordados sobre a gestão e na última seção são apresentadas as considerações finais.

\subsection{Contextualização e características da empresa familiar}

A empresa familiar é um tema recorrente, amplamente debatido devido a sua importância e contribuição na economia (Silva et al., 2017). Estas empresas possuem definições abrangentes entre os autores, para (Alderson, 2011) existem três características importantes que compõe essa definição, sendo elas: a necessidade de ocorrer pelo menos duas gerações no controle da empresa, com pelo menos $5 \%$ das ações sendo detidas pela família; definira estratégia da empresa de acordo com o objetivo de ser uma empresa familiar, ou seja, se tornar uma organização com sua gestão realizada por membros de uma mesma família, com organização sustentável ao longo das gerações; e no mínimo um dos controladores ligado à família deve dispor do poderio de eleger o presidente do conselho e o CEO, ou um membro da família precisa ser responsável pela gestão e 
pretende dar continuidade na empresa para que haja futuras gerações (Troccoli et al., 2018).

Astrachan et al., (2003) propõe três definições para essa temática. Na primeira, sugere que em uma empresa familiar, a maior parte das ações ordinárias pertencem a uma ou mais famílias; a segunda propõe que as empresas familiares são aquelas em que, a família não só detém ações que proporcionam o poder de voto, mas também possuem cargos diretivos dentro da empresa; na terceira definição, mais restrita, afirma que uma empresa familiar plena é concebida somente depois que houverem sucessões dos membros da família no controle da mesma (Goes et al., 2017)

As empresas familiares são responsáveis por grande parte do PIB e geração de emprego, por isso, assumem um papel muito relevante nos negócios em todo o mundo (Borges \& Machado, 2017). Em um estudo de Robertsson, et al. (2021) que reuniu as maiores empresas da de 2021 da categoria, foi evidenciado a importância destas empresas, o trabalho apontou que estas são vitais para a estabilidade da economia global; entre as empresas listadas por possuir um grande sucesso econômico é possível encontrar a Ford Motor Company., Wal-Mart Inc, Coca-Cola Consolidated, Inc., Nike Inc. e empresas brasileiras como a Companhia Siderurgica Nacional, Magazine Luiza SA, JBS AS e Votorantim Participações S.A.

Os valores, os vínculos entre seus membros, a associação entre a família e a empresa, o processo sucessório e a imagem do fundador importante na identidade distinguem essa organização das demais (Miranda, 2019).

Gersick et al. (1997) propôs um modelo para representar as empresas familiares através de seus três pontos principais: família, propriedade e gestão (Figura 1).

Figura 1: Modelo de três círculos.

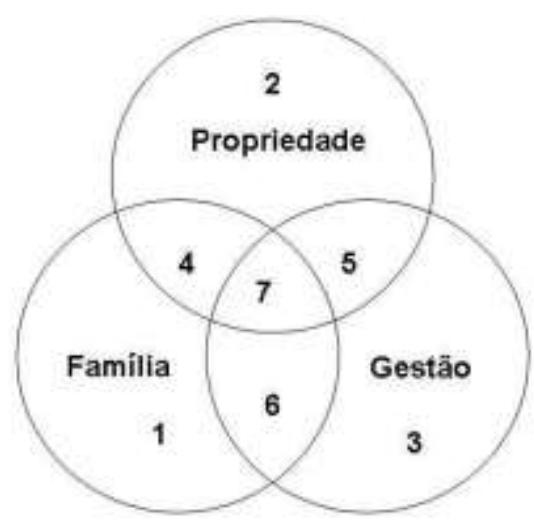

Fonte: Gersick et al. (1997, p. 6)

De acordo com a figura são definidos sete grupos que permitem entender qualquer posição nas empresas familiares, são estes: (1) familiares sem participação na propriedade e gestão; (2) sócios-proprietários não gestores e não familiares; (3) gestores não familiares e não proprietários; (4) familiares proprietários que não participam da gestão; (5) proprietários gestores que não tem vínculo familiar; (6) gestores familiares não proprietários; e (7) familiares, proprietários e gestores (de Oliveira et al., 2011).

Existem fatores que contribuem de forma positiva para a gestão das empresas familiares como a imagem forte de um fundador capaz de definir uma cultura organizacional bem estabelecida para e trazer uma singularidade na gestão, além disso, os membros da empresa agem de forma mais prudente devido à preocupação com seu patrimônio investido (Muritiba et al.,2016; Miranda, 2019). Não obstante, é necessário destacar que nos momentos de dificuldade dessas empresas ocorre uma 
maior entrega dos membros da família para superar as dificuldades e perpetuar os negócios, além de uma questão de orgulho, a família tende a se empenhar mais para dar continuidade na empresa em suas próximas gerações (Donnelley, 1967; Lodi, 1993; Ricca, 1998).

Ao elencar vantagens da empresa familiar, são encontradas: a sucessão familiar no comando da empresa; processo decisório ágil e elevada versatilidade para implementar ações; abertura para treinamento mais extenso e intenso dos membros da empresa; apresentar um sucessor interessado de forma societário no aperfeiçoamento dos resultados atuais e posteriores da empresa; e o conhecimento mais profundo sobre este sucessor (Santos et al., 2021). Os valores de confiança e solidariedade do ambiente familiar tendem a ser agregados na empresa e a gestão destas termina por priorizar o vínculo entre parentes dentro da organização, sendo importante ressaltar que estes valores podem ser atribuídos a características positivas da empresa, desde que não configure um entrave ao profissionalismo (Borges et al., 2017).

A organização de origem familiar pode tornar-se um ambiente favorável aos surgimentos de conflitos específicos que podem resultar em problemas no desempenho da empresa. Existe a possibilidade de a empresa ser prejudicada por uma informalidade excessiva, proveniente dos convívios dos membros da empresa em seu ambiente familiar, até mesmo reproduzindo o ambiente doméstico dentro da empresa, sua hierarquia e favoritismo, com a promoção de parentes acima de competências profissionais e de modo que os controles formais da empresa sejam prejudicados (Vinagre et al., 2017). Citando as desvantagens, são listadas: frequentes disputas pelo poder entre os membros da família; complexidade na separação do papel desempenhado no ambiente familiar e na empresa e resistência na demissão do sucessor, mesmo que este não apresente um desempenho satisfatório. (Santos et al., 2021).

Oliveira (2000) relatou que apenas 30\% das empresas desenvolvidas como empresas familiares conseguem fazer a sucessão para uma segunda geração e apenas 5\% chegam a terceira geração, além disso, 70\% das empresas no Brasil não dão continuidade na empresa familiar após a morte do seu fundador. Portanto, é necessário definir um modelo de gestão bem estruturado e planejado que permita contornar as desvantagens e usufruir das particularidades da empresa familiar que agreguem vantagens frente as demais empresas.

\subsubsection{Estratégias de gestão na empresa familiar}

Usualmente, as empresas familiares não seguem os modelos tradicionais de gestão, pois sua estruturação é permeada por demandas de membros da família, até mesmo a necessidade da harmonia da família, que resultam na diminuição da motivação da equipe e como consequência maior, em alguns casos, no fim da empresa.

Em detrimento de outras empresas as organizações familiares apresentam características particulares que as caracterizam e sua existência está vinculada a características e desafios presentes em três esferas: a família, a empresa e a gestão (Andrade et al. 2005)

Uma característica positiva na gestão de empresas familiares é a dedicação e responsabilidade da família perante o sucesso e gestão da empresa. Nestas organizações o gestor deve reduzir ou até mesmo solucionar conflitos interpessoais que tendem a ser recorrentes nestas organizações (Ruffatto et al., 2017).

As características específicas deste tipo de organização, como a importância das relações entre familiares e os negócios, permitem uma nova abordagem estratégica na disposição da empresa para uma estruturação eficiente (Acquaah, 2013). Dentro, dessa abordagem é importante avaliar estratégias na gestão que englobem o processo sucessório, a importância da tradição e valores familiares e a tomada de decisão. 


\subsection{Processo Sucessório}

As empresas familiares são importantes na economia mundial, influenciam o PIB, a geração de empregos e o desenvolvimento econômico e social. O principal ponto crítico para a continuidade da empresa através das gerações é o processo sucessório (dos Santos et al., 2020). Denomina-se sucessão o procedimento no qual o atual dirigente da empresa transfere tanto o patrimônio quanto o poderio da empresa para o próximo dirigente. Através da sucessão são delegadas responsabilidades que visam garantir a continuidade da empresa, seu desenvolvimento e crescimento.

A sucessão nada mais é que a transferência do controle da empresa, e se for realizada de forma estratégica possibilita perpetuar os valores do fundador e manter ou até mesmo aumentar seu desemprenho frente as outras empresas do mercado, por isso, é um procedimento de suma importância. Com o intuito de assegurar a continuidade dos negócios o fundador/antecessor e o sucessor estabelecem compromissos relacionados a gestão e controle da empresa incluindo a participação dos membros da família no processo (Duarte, 2006).

A sucessão, no entanto, não é apenas um procedimento pontual e demanda um longo processo que precisa ser previamente estruturado, planejado e só então estabelecido. Esse processo muitas vezes pode estar associado a conflitos internos e até mesmo disputas pela sucessão, pois, muitos empresários não concebem a ideia de serem sucedidos até que seja necessário seu afastamento da empresa. O fundador precisa entender a importância do processo sucessório na avaliação do desempenho do sucessor e ao delegar tarefas e permitir que este tenha autonomia, gera a noção de que a sucessão está vinculada com competências, habilidades e comprometimento (Silva, 2014; Miranda, 2019).

A sucessão precisa ser bem estabelecida pois a falta de sucessores capacitados para as posições centrais da empresa tem como consequência a perda do valor de mercado (Groves, 2018; Dutra et al., 2020). De acordo com algumas pesquisas se analisar um panorama de 100 empresas que visam ser familiares, apenas 30 chegam a segunda geração familiar e esse número diminui ainda mais quando se trata da terceira geração (Vinagre et al., 2017). O processo sucessório também permite que seja escolhido o sucessor dentre os membros da família que mais apresenta o perfil da empresa para ser responsável pela gestão.

Embora haja muitas características comuns nas empresas familiares cada uma apresenta suas particularidades que devem ser consideradas no planejamento do processo sucessório, sendo este essencial na continuidade da empresa. O ambiente familiar possui particularidades de sentimentos e emoções, que podem ser transmitidos para o ambiente empresarial (Vinagre et al., 2017). A gestão de sucesso em uma empresa familiar depende de um planejamento estratégico para a saída do fundador. Durante a sucessão, sucessor pode não ser uma representação fiel de seu antecessor no que diz respeito a sua forma de gerir a empresa e empreender (Rosa, 2018). Estudos relatam que muitas organizações familiares encerram suas atividades na morte do fundador, demonstrando que a visão do negócio estava fortemente vinculada ao fundador, de forma que, os sucessores não consigam ou mesmo não queiram dar continuidade na empresa (Lodi, 1993; Vinagre et al., 2017)

A sucessão pode agregar vantagens para a empresa familiar, por iniciar uma nova gestão acompanhada de um novo direcionamento estratégico que podem agregar no crescimento dos negócios (Tillmann et al., 2005). A preparação do sucessor é essencial e exige o entendimento da família tanto em relação a escolha do sucessor como nas ações que redirecionam a gestão da empresa com a mudança do gestor. Há a necessidade de implementação do processo sucessório de forma sistemática, com atenção especial a sobreposição das dimensões da família na organização (Teston et al., 2016)

Investir na capacitação profissional dos membros da família é parte de uma boa estratégia de gestão. Os membros envolvidos em atividades na empresa, especialmente aqueles que participam da gestão, quando bem preparados para suas funções permitem o bom desempenho da empresa, além de evitar conflitos com funcionários fora da família que estão cientes do favoritismo pela família em empresas familiares. A continuidade da empresa por meio de gerações exige uma atenção permanente a conflitos de interesse na gestão (Miranda, 2019). 


\subsection{A importância da tradição e valores em empresas familiares}

A vivência de cada família atua na construção de seus valores e afeta a cultura organizacional da empresa, influenciando modelo de gestão e a tomada de decisão tanto na tomada de decisão quanto no modelo de gestão (Coimbra et al., 2020). A cultura organizacional está vinculada a compreensão e o compartilhamento das normas, valores, crenças, modo de pensar que determinam diretrizes e ações na empresa, onde é válido ressaltar as maneiras pelas quais essas normas e valores são transmitidos a outros membros da organização (Daft, 2014; Farah, 2019)

A tradição e os valores das empresas são de suma importância na gestão e na história destas, essa importância é acentuada quando as organizações são familiares, buscando manter e perpetuar seus valores nas próximas gerações. A família exerce elevada influência na gestão dos negócios e tende a preservar os valores familiares (Oro et al., 2017). Os vínculos afetivos influenciam o desempenho e decisões da empresa, mas também ocorre a formação de laços entre funcionários e os proprietários, fortalecendo a transmissão de valores da empresa e a confiança mútua (Dante et al., 2016).

O desenvolvimento da empresa tende a ser beneficiado pelos valores transmitidos, se houver conciliação entre os valores da família e o profissionalismo (Borges et al., 2017). A tradição de uma empresa é importante, mas não deve ser instituída de uma maneira inflexível que não permita a abertura para inovações necessárias para o desenvolvimento da empresa. As empresas familiares podem ser consideradas conservadoras, com dificuldades a adaptação a mudanças, rígidas e hierarquizadas. (Coimbra et al., 2020).

As vantagens relacionadas ao tradicionalismo da empresa familiar podem ser observadas pelo respeito e influência exercida pela empresa, vasto conhecimento e dedicação ao negócio por seus membros, compartilhamento de valores e lealdade dos membros familiares a empresa (Adachi,2006).

Goetschin (1987) propôs um modelo de dois círculos para representar a empresa familiar, sendo um deles a família, o outro a empresa e a interseção entre os círculos corresponde a especificada da relação entre empresa e família. É necessário salientar que cada uma dessas esferas apresenta seus respectivos valores e por isso há um conflito de interesses entre o círculo da família (lado emocional) e o círculo da empresa (lado racional que tem como objetivo maior o lucro da empresa).

Os valores da empresa são representados pelo lucro, competitividade, crescimento, competitiva de e inovações; já os valores da família são a afetividade entre os membros, tradição, segurança e hereditariedade. Os valores acima citados podem gerar conflitos e dificuldades na tomada de decisão dos negócios, pois esses valores abrangem as necessidades específicas da família e da empresa (Rodrigues, 2019).

Em empresas familiares, salienta como vantagem um fundador que, comumente, demonstra, grande envolvimento e comprometimento a empresa, dessa forma, o fundador tende a direcioná-la para a preservação de seus valores e objetivos (Souza, 2002; Borges et al., 2017).

A imagem do fundador da empresa é de suma importância nos negócios, é uma figura sempre lembrada pelos seus valores e visão empreendedora que deram origem a empresa, a ausência do fundador possibilita, portanto, uma ruptura dos antigos valores que a figura do líder proporciona. Essa ausência tem como consequência a redistribuição do poder e uma modificação hierárquica, os papeis e incumbências dos membros familiares podem ser alterados bem como suas responsabilidades organizacionais e sociais (Miranda, 2019).

\subsection{A importância da tradição e valores em empresas familiares}

Observando o amplo espectro de empresas e de um mercado progressivamente mais competitivo a cada ano, é necessário desenvolver modelos de gestão adequados para o perfil da empresa que levem em consideração e facilite a tomada de decisão (dos Santos et al.,2020). Estratégias na tomada de decisões tem como objetivo minimizar erros, diminuir incertezas e extinguir decisões sem planejamento (Maximiano, 2016). 
Decisões são questões recorrentes dentro do ambiente empresarial e para que o processo de tomada de decisão seja feito de forma correta é preciso, primeiramente, que a organização apresente mecanismos eficientes de coletas de dados para posterior análise, dessa forma o gestor sempre estará pautado no controle da empresa para facilitar decisões. (Silva et al., 2017).

O uso de tecnologias de acesso a informações e armazenamento de dados, podem auxiliar a gestão ao propiciar maior embasamento na tomada de decisões. (Borges et al., 2017).

Alguns fatores que integram o processo de tomada de decisão foram elencado por Chiavenato (2006), sendo estes: o tomador de decisão (pessoa ou grupo de pessoas responsáveis por decidir entre as opções qual se enquadra melhor nos objetivos da empresa; estado de natureza (certezas, dúvidas e riscos); objetivo a ser alcançado após as decisões; prioridades (pontos essenciais a serem considerados na tomada de decisão); situações específicas que podem ter influência; estratégias (ações que utilizam os recursos disponíveis da empresa para que o objetivo seja atingido); resultado (consequência da estratégia).

A tomada de decisão pode ser afetada por vínculos que envolvem emoções e sentimentos na gestão da empresa, impossibilitando uma tomada decisões (Vogt et al., 2017). Em um estudo sobre a influência das emoções na estratégia empresarial das empresas familiares Kellermanns et al. (2014) demonstraram a importância de avaliar qual o impacto das emoções na tomada de decisão das empresas familiares, visto que emoções relacionadas a divórcio, doença e sucessão dentro do ambiente familiar pode afetar diretamente a gestão. As necessidades específicas da família e da empresa geram conflitos de interesses que afetam diretamente a tomada de decisão que é definida tanto por valores emocionais como racionais (Rodrigues, 2019).

Dentro da gestão de empresas familiar, os gestores comumente assumem uma postura mais prudente, sendo menos propensos a tomar decisões em que precisem assumir riscos para aumentar o desempenho da empresa ou participar de ações que aumentam a variabilidade do mesmo, isto ocorre porque os gestores se preocupam, além da continuidade da empresa, com sua riqueza socioemocional (Gómez-mejía et al., 2007; Vogt et al., 2017).

Apesar da influência familiar os gestores de empresas familiares podem ser altamente capacitados para realizar a tomada de decisão de forma analítica e precisa, as decisões intuitivas, independente da origem da empresa, podem fazer parte da estratégia da gestão (Goes et al., 2007).

\section{Metodologia}

A pesquisa é considerada descritiva pois demanda que o investigador colete diversas informações sobre o tema pesquisado com o objetivo de descrever não somente os fatos, mas também os acontecimentos referentes a eles estudados (Triviños, 1987). O método descritivo neste estudo associa o processo de estruturação da empresa familiar com as suas variáveis na gestão.

O método escolhido foi a pesquisa exploratória que permite esclarecer, ampliar e alterar conceitos. Este método tem por objetivo conhecer a variante de um estudo, estruturar e organizar os dados sobre o tema, facilitando a obtenção de informações, a delimitação dos dados, e a enumeração das hipóteses. Deste modo, é possível a formulação de problemas e hipóteses bem definidos que podem ser estudados em trabalhos futuros. Este método fornece a possibilidade de formular ideias e insights para preencher lacunas dos problemas abordados. A pesquisa exploratória consiste em um estudo contínuo do problema, que possibilita compreender de forma qualitativa um problema do qual inicialmente pouco se sabia (Martelli et al., 2020).

Os objetivos exploratórios mais amplos permitem iniciar a pesquisa qualitativa, que proporcionará foco para o estudo (Silva et al., 2018). O método qualitativo, segundo Bauer et al., (2002) foca na descoberta da descrição e na compreensão das 
relações múltiplas de um ambiente de estudo. A análise qualitativa está relacionada por um lado com os significados diferentes (na abordagem objetiva e subjetiva) dos elementos de estudo, e por outro, a variação de acordo com os interesses individuais ou de grupos (Silva et al., 2018).

O segundo método de pesquisa pode ser definido como aplicado, pois, o estudo tem por objetivo gerar conhecimentos que possam ser usados de forma prática, auxiliando na resolução de temáticas propostas, envolvendo assuntos explorados e discutidos anteriormente. Utilizou-se de pesquisa bibliográfica, que é definida por fichamento, leitura, seleção e organização e de temas de interesse e, posteriormente, a análise de estudos de casos presentes da literatura, que objetiva examinar aspectos práticos a respeito dos assuntos pautados no desenvolvimento do trabalho (Fleury \& da Costa Werlang, 2016).

\section{Resultados}

\subsection{Processo Sucessório}

O processo sucessório, antes de ser iniciado, precisar ser avaliado sete componentes estabelecidos por Lodi (1994): (1) os valores da família designados pelo fundador e que devem prevalecer nas gerações; (2) as relações de poder; (3) a ética interpessoal (4) o dado comportamental que determina o padrão de interações psicológicas; (5) os interesses patrimoniais; (6) o acesso à competência profissional; (7) a instrumentação jurídica.

Ao definir uma boa estratégia no processo sucessório é necessário, primeiramente avaliar três possibilidades e considerar qual se adequa mais ao perfil da empresa, seus recursos e demandas. Tabela 1 apresenta os 3 estágios do processo sucessório, sendo estes, planejamento de reposição planejamento sucessório com ênfase no desenvolvimento e planejamento sucessório com ênfase nas necessidades estratégicas do negócio, bem como suas características, vantagens e desvantagens.

Tabela 1: Estágios do processo sucessório.

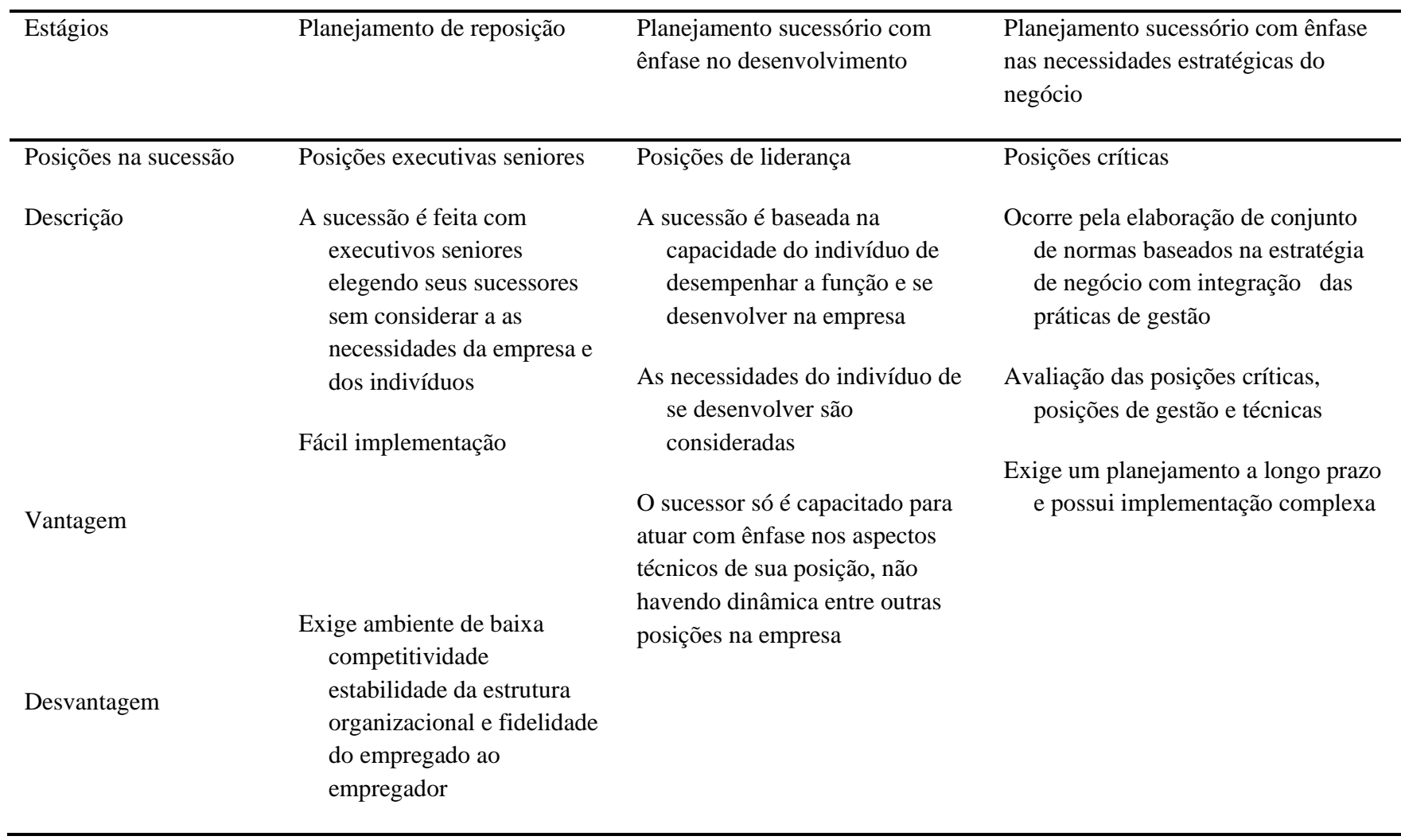


Outros autores trazem essas abordagens como estágios, de forma que durante o desenvolvimento de uma empresa ela usufrua das três abordagens em momentos diferentes.

\subsection{A importância da tradição e valores nas empresas familiares}

Diversas vezes o conceito de empresa familiar é associado erroneamente com conservadorismo e recusa em aderir a inovações necessárias nos negócios. No entanto, trabalho, de da Silva et al. (2018) é citado a importância do valor do tradicionalismo em algumas organizações como, por exemplo, métodos tradicionais de antepassados que são mantidos no processo produtivo, agregando um maior valor a aquele trabalho, moldando a maneira que as atividades na empresa são realizadas e a percepção pelo cliente.

Normas, valores e crenças são transmitidos dentro de empresas compondo a cultura organizacional associada ao fundador (Farah, 2019). A cultura organizacional prioriza os valores afetivos que permeiam as empresas familiares, essa cultura é constantemente afetada pelo compromisso da família com a empresa. Em instituições influenciadas por parentesco há maior susceptibilidade desses conceitos determinarem as diretrizes da organização. A tradição pode ser um aspecto importante na empresa familiar, tanto por participação na cultura organizacional, quanto por sua valia frente ao mercado. A tradição pode remeter a sensação de confiabilidade, segurança e experiência da empresa em proporcionar um produto ou serviço.

Os critérios relacionados a valores e tradições de empresas familiares são por um lado as vantagens em preservar os valores e tradições na empresa familiar e por outro lado fatores a serem considerados diante de decisões conflitantes entre tradições e inovações.

Como vantagens são observadas a confiabilidade, segurança, riqueza socioemocional, disseminação de valores da empresa para as futuras gerações, criação de uma identidade empresarial, identificação dos membros as empresas com a cultura organizacional e valor agregado para os clientes.

Como fatores a serem considerados diante de decisões conflitantes entre tradições e inovações são observados: a necessidade de manter a flexibilidade frente a mudanças necessárias para o bom desempenho da empresa, não manter a rigidez diante de propostas de mudanças de executivos que não pertencem a família e adequação da empresa as exigências do mercado.

\subsection{Tomada de decisão}

Outrossim, a tradição pode ser relacionada à confiança e credibilidade da empresa, devido há anos de experiência no mercado. Remeter a valores tradicionais e a imagem forte de um antecessor em campanhas publicitárias da empresa ou até mesmo na preparação de sua equipe pode ser um ponto favorável para o fortalecimento da empresa. Para tal, é necessário sempre reavaliar se os valores devem ser preservados e a forma de transmitir isso para novos membros da empresa e clientes de maneira apropriada, demonstrando que tradicionalismo é diferente de conservadorismo, inflexibilidade e rejeição a novas ideias dentro da empresa. São definidos quatro modelos de tomada de decisão: o modelo racional, processual, político e anárquico (Choo, 2003).

A tomada de decisão racional pode ser utilizada quando há uma grande disponibilidade de informações, onde todas serão relevantes no processo decisório. Ocorre a toma de decisão de forma racional, levando em consideração os objetivos da empresa, estratégias disponíveis, resultados esperados e a importância desses resultados. A tomada de decisão racional em uma empresa familiar pode ser afetada e até mesmo impedida pelo conflito de interesses entre os membros da empresa, a falta de informações também prejudica a tomada de decisões em empresas com controles mais informais. Simon (1965) também salienta que não é possível prever os resultados de forma tão realista para tomar uma decisão de forma exclusivamente racional no âmbito de obter a melhor estratégia com menor custo. 
A tomada de decisão processual é capaz de abranger ambientes mais complexos e dinâmicos, dessa forma, para este modelo não são necessárias a ampla gama de informações do modelo de decisão racional. Como definido, este modelo de decisão é processual, ou seja, são realizados ajustes necessários ao longo do tempo, permitindo uma maior flexibilidade nas decisões da empresa, que têm como foco resultados a longo prazo. Devido a essas características eles são indicados para contexto de interdisciplinaridade na tomada de decisão (Harrison, 1993).

A tomada de decisão processual, consiste na identificação do problema, desenvolvimento de alternativas para solucionar o problema e seleção entre as alternativas para solucioná-lo de forma mais eficaz, Choo (2003). Por se tratar de uma decisão processual, as etapas são reavaliadas de acordo com os resultados gerados pelo processo decisório.

O modelo político de tomada de decisão é um modelo utilizado como ferramenta quando pessoas de posições hierárquicas e influência distinta dentro da empresa são responsáveis por tomar decisões em conjunto, sendo amplamente afetadas pelos cargos ocupados pelos gestores e impedindo tomada de decisão racional (Vieira et al., 2014). Em uma empresa familiar a tomada de decisão baseada em um modelo político, eventualmente, resultará em decisões mais próxima as da família e seus membros que ocupem cargos mais elevados, podendo resultar em um conflito de interesses.

O modelo de decisão anárquico parte do pressuposto que a organizações podem ser consideradas anarquias organizadas, e as situações envolvem preferências controversas. (Choo, 2003). Embora a participação dos envolvidos seja distribuída de maneira mais igualitária no processo decisório sem o peso de decisões imparciais, este modelo é caraterizado como falho pelas poucas definições no estabelecimento de tempo, esforço e estratégia dedicada ao problema por casa um dos membros da empresa.

\section{Discussão}

\subsection{Processo sucessório}

Ao comparar os três estágios do planejamento sucessório, sendo eles, Planejamento de reposição, Planejamento sucessório com ênfase no desenvolvimento e Planejamento sucessório com ênfase nas necessidades estratégicas do negócio, é possível avaliar uma evolução gradativa, na preparação da equipe da empresa, portanto, inicia-se o processo sucessório com uma reposição e, ao final a empresa utiliza de um processo sucessório de alinhamento às necessidades estratégicas. Esse estágio final exige uma equipe bem preparada para se adaptar ao contexto de transformação da empresa (Medeiros et al., 2019). Em empresas maiores os estágios de sucessão são dinâmicos para cada posição dentro da equipe, levando em consideração critérios como tempo na empresa, competências, teste de análise de perfil, nível de responsabilidade e critérios informais, evidenciado pelo estudo (Maillard, 2020).

Portanto, o processo sucessório pode ser desenvolvido considerando cada estágio e a demanda da empresa.

Maillard (2020) demonstrou que os três estágios têm objetivos diferentes. No estágio de reposição é possível realizar a identificação de backups, além de realizar uma sucessão imediata. No estágio de desenvolvimento o objetivo é o desenvolvimento de indivíduos para posições específicas no futuro e o estágio de necessidades estratégicas desenvolve um pool de talentos para o futuro.

Em empresas familiares existe uma predisposição ao planejamento de reposição no processo sucessório em posições executivas seniores devido a vínculos afetivos e necessidade de transmitir o poder por meio das próximas gerações, ainda assim, esse processo pode ser realizado de forma gradual e focada na competência do sucessor. Um aspecto importante do processo sucessório é justamente ser visto com um processo e não uma etapa pontual. A sucessão deve ser planejada a longo prazo, possibilitando que o sucessor tenha um contato maior com a equipe da empresa, entenda as particularidades do trabalho desenvolvido na empresa pelo seu antecessor e tenha domínio das estratégias de gestão pré-estabelecidas. 
Além disso os demais membros da família que participam da empresa podem assumir posições críticas ou de liderança de acordo com suas competências e desenvolvimento dentro da empresa. Assim, para que haja o crescimento da empresa familiar é necessário o foco em uma gestão estratégica que inclua a família e sua sucessão nas futuras gerações, mas não devido somente pelo nepotismo. O processo sucessório dentro da empresa familiar, quando bem estabelecido, pode favorecer a confiança e segurança na empresa, tanto para equipe como para os clientes.

\subsection{A importância da tradição e valores nas empresas familiares}

Em empresas familiares existe um valor distinto a ser preservado na gestão: a riqueza socioemocional. Portanto, os objetivos da empresa envolvem o equilíbrio e reputação da empresa (Gómez-mejía et al., 2007).

Uma maneira de manter a tradição e valores na empresa é avaliar quais valores devem ser mantidos, quais valores, ao longo da trajetória, foram favoráveis a gestão e prosperidade.

O compartilhamento de valores, apego emocional a empresa e o notório vínculo social presente nas organizações familiares em grande parte são devido a história e tradição da família na construção da empresa e na sua luta apara atingir seus objetivos. A sucessão entre familiares, perpetua os vínculos, mantém a tradição e demonstra a confiabilidade nos membros da família para uma estão eficientes (Berrone et al.,2012).

Outrossim, a tradição pode ser relacionada à confiança e credibilidade da empresa, devido há anos de experiência no mercado. Remeter a valores tradicionais e a imagem forte de um antecessor em campanhas publicitárias da empresa ou até mesmo na preparação de sua equipe pode ser um ponto favorável para o fortalecimento da empresa. Para tal, é necessário sempre reavaliar se os valores devem ser preservados e a forma de transmitir isso para novos membros da empresa e clientes de maneira apropriada, demonstrando que tradicionalismo é diferente de conservadorismo, inflexibilidade e rejeição a novas ideias dentro da empresa.

\subsection{Tomada de decisão}

O processo de tomada de decisão faz parte do trabalho de qualquer membro da empresa, porém para os gestores existe uma responsabilidade maior vinculada, de forma que decisões são parte de sua função na empresa. O método anárquico pode não ser considerado ideal para diversas situações por ser evasivo e pouco estabelecido; enquanto, o método político permite uma comunicação maior entre membros com posições hierárquicas diferentes, mas em muitos casos não é indicada por estar associada a conflitos de interesses (dos Santos et al., 2020).

Para Vieira et al. (2014) não há um modelo ideal para a tomada de decisão dentro de empresas familiares e sim, modelos ideais para situações pré-estabelecidas, pois os modelos acima citados podem ser utilizados em empresas familiares na resolução de problemas.

Apesar da particularidade de cada empresa, em empresas familiares, dois modelos de decisão podem ser considerados ideias, sendo eles: o modelo racional e o processual. O modelo racional é melhor utilizado quando há informações suficientes para orientar o processo de tomada de decisão, a justificativa é que as vertentes consideradas são vinculadas unicamente com o desempenho da empresa: estratégia, resultados e objetivo. Dessa forma, os conflitos familiares são minimizados no processo de decisão.

O outro método que deveria ser utilizado, o processual, baseia a tomada de decisão em resultados, de modo que, estes resultados podem ser reavaliados com frequência. É um método que também usa dados concretos para a solução de problemas, mas neste caso não há tanta disponibilidade de informação quanto no método racional. Ainda assim, os conflitos de interessem não tem grande influência das decisões e soluções propostas podem ser reavalias constantemente. 


\section{Considerações Finais}

O objetivo do presente trabalho foi analisar os desafios encontrados na gestão de empresas familiares e sugerir métodos para uma gestão mais eficiente.

Muitas empresas familiares estão dentre as mais bem sucedidas do mundo e representam parte importante da economia global, por isso, é importante desenvolver modelos de gestão eficientes para essas organizações que abrangem desde pequenas empresas tradicionais até empresas como a JBS, Magazine Luiza e Walmart.

No estudo foram apontados três desafios que permeiam a estratégia de gestão e por meio da literatura foi possível constatar a influência das relações no processo sucessório, no modelo de tomada de decisão e imagem de inflexibilidade relacionada ao tradicionalismo. Cada empresa familiar tem suas peculiaridades, além de desafios comuns a todas as empresas, mas através de análises dos estudos presentes na literatura é possível aprender sobre a gestão e encontrar soluções que sejam comuns a grande parte das empresas familiares.

É possível constatar que o processo sucessório com o devido planejamento e profissionalização do sucessor pode representar não só um processo necessário de reposição na gestão, mas uma oportunidade de crescimento da empresa e continuidade ao longo das gerações. Também, vale ressaltar que os métodos racionais e processuais podem colaborar com o processo de tomada de decisão dentro de organizações familiares, de maneira mais objetiva e sem influências de vínculos afetivos que geram incertezas.

O tema abordado tem muito a ser explorado e mais trabalhos são necessários no estudo deste tema de suma importância na economia e no mercado mundial.

\section{Referências}

Acquaah, M. (2013). Management control systems, business strategy and performance: A comparative analysis of family and non-family businesses in a transition economy in sub-Saharan Africa. Journal of Family Business Strategy, 4(2), 131-146. https://doi.org/10.1016/j.jfbs.2013.03.002

Adachi, P. P. (2006). Família SA: Gestão de empresa familiar e solução de conflitos. São Paulo: Atlas, 458-476.

Albuquerque Filho, A. R., Ribeiro Macedo, F. F. R., Moura, G. D. D., Bracht Fank, D. R., \& Heberle, E. L. (2019). Fatores determinantes da intangibilidade em companhias abertas familiares. Revista de Contabilidade do Mestrado em Ciências Contábeis da UERJ, 23(2), 37-52.

Alderson, K. (2011). Understanding the family business. Business Expert Press.

Andrade, D. M.; Grzybovski, D. \& de Lima, J. B. (2005). Aplicabilidade do "modelo dos três círculos" em empresas familiares brasileiras: Um estudo de caso. Revista Eletrônica de Administração, 11(5), 1-25.

Astrachan, J. H., \& Shanker, M. C. (2003). Family Businesses' Contribution to the U.S. Economy: A Closer Look. Family Business Review, 16(3), $211-219$. https://doi.org/10.1177/08944865030160030601

Bauer, M. W., \& Gaskell, G. (2017). Pesquisa qualitativa com texto, imagem e som: um manual prático. Editora Vozes Limitada.

Berrone, P., Cruz, C., \& Gomez-Mejia, L. R. (2012). Socioemotional wealth in family firms: Theoretical dimensions, assessment approaches, and agenda for future research. Family business review, 25(3), 258-279.

Buchweitz, M. J. R., Cruz, A. P. C. da, Barbosa, M. A. G., \& Pereira, T. A. (2019). A riqueza socioemocional e o declínio em uma empresa familiar: Um estudo da Guerra S.A. RACE - Revista de Administração, Contabilidade e Economia, 18(2), 231-258. https://doi.org/10.18593/race.19059

Borges, B., \& Machado, G. (2017). O processo de tomada de decisão em empresas familiares de pequeno porte: Um estudo de casos múltiplos em organizações prestadoras de serviços em Alvorada/RS. Revista Acadêmica São Marcus 7(2), 61-101.

Chiavenato, I. (2006). Princípios da administração: o essencial em teoria geral da administração. Editora Manole.

Coimbra, D. G., Souza Júnior, A. A. de, \& Moraes, A. F. D. M. (2020). Aspectos da Dominação Masculina no Processo Sucessório em Empresas Familiares do Setor Automotivo. Revista de Administração IMED, 10(2), 158-177. https://doi.org/10.18256/2237-7956.2020.v10i2.3969

Dante, F. S., Rodrigues, R. M., \& Cremonezi, G. G. (2016). os impactos da gestão familiar nos conflitos e cultura organizacional. Revista de Carreiras e Pessoas (ReCaPe) ISSN 2237-1427, 6(2). https://doi.org/10.20503/recape.v6i3.31067

Daft, R. (2014). Organizações: Teoria e projetos. 11 ed. São Paulo: Thomson Learning. Pioneira. Dante, F. S., Rodrigues, R. M., \& Cremonezi, G. G. (2016). Os impactos da gestão familiar nos conflitos e cultura organizacional. Revista de Carreiras e Pessoas (ReCaPe) ISSN 2237-1427, 6(2). https://doi.org/10.20503/recape.v6i3.31067 
Silva, C. R. et al. (2018). Valores familiares e práticas de gestão: um estudo de caso na agroindústria "L” em Venda Nova do Imigrante - ES. https://admpg2018.com.br/anais/2018/arquivos/05072018_030549_5aeff5e1c9b2c.pdf

Oliveira, J. L., Álvares, E., Pinheiro, A. S., \& Pimentel, T. D. (2011). A Governança corporativa como elemento mediador na empresa familiar. Revista de Administração FACES Journal.

Donnelley, R. G. (1967). A empresa familiar. Revista de administração de empresas, 7(23), 161-198.

Santos, M. C., dos Santos, A. F., Moreira, A. L. D., \& dos Santos, D. F. Análise do processo da tomada de decisão em empresas familiares. https://aprepro.org.br/conbrepro/2020/anais/arquivos/09212020_200900_5f693e089b420.pdf

Santos, S. P., de Souza, R. F., \& Macedo, L. R. (2021). A relevância do fluxo de caixa para a gestão em uma empresa familiar. Scientia: Revista Científica Multidisciplinar, 6(1), 183-203.

Duarte, F. D. (2006) Proposta para avaliação do processo sucessório em empresas familiares. 2006. Dissertação (Mestrado em Administração e Negócios). Pontifícia Universidade Católica do Rio Grande do Sul, Porto Alegre.

Dutra, T. A., Bose, M., Nascimento, F., \& Salomão, G. R. (2020). Processo sucessório e seu vínculo com a estratégia organizacional: Um estudo de casos múltiplos. Revista de Carreiras e Pessoas, 10(1). https://doi.org/10.20503/recape.v10i1.45921

Farah, B. C. R. (2019). Cultura organizacional em uma empresa familiar: Estudo de caso no ramo de materiais de construção. https://bdm.unb.br/handle/10483/25160

Ferreira, M. A. de A. (2015.Processo sucessório em organizações brasileiras: um estudo com uso de ground theory.Tese (Doutorado em Ciêncas). Universidade de São Paulo, São Paulo, Brasil. https://doi.org/10.11606/T.12.2015.tde-29062015-155504

Fleury, M. T. L., \& da Costa Werlang, S. R. (2016). Pesquisa aplicada: conceitos e abordagens. Anuário de Pesquisa GVPesquisa.

Frezarin, A. L., Andrade, B. O. C. de, Rossi, F. C., \& Antonio, H. M. (2021). Desafios da gestão em uma empresa familiar. http://ric.cps.sp.gov.br/handle/123456789/6121

Gersick, K. E., Davis, J. A., Hampton, M. M., \& Lansberg, J.(1997). De geração para geração: ciclos de vida das empresas familiares (N. Montingelli Jr., Trad.). Negócio.

Gómez-Mejía, L. R., Haynes, K. T., Núñez-Nickel, M., Jacobson, K. J., \& Moyano-Fuentes, J. (2007). Socioemotional wealth and business risks in familycontrolled firms: Evidence from Spanish olive oil mills. Administrative science quarterly, 52(1), $106-137$.

Goes, T. H. M., Martins, H. H., \& Machado Filho, C. A. P. (2017). Desempenho financeiro de empresas com características familiares: Análise de empresas brasileiras listadas na BM\&F. REGE-Revista de Gestão, 24(3), 197-209.

Goetschin, P. (1987). La gestion de la succession dans les PME. Revue économique et sociale, Lausanne, 98-107.

Gomez-Mejía, L. R., Haynes, K. T., Núñez-Nickel, M., Jacobson, K. J. L., \& Moyano-Fuentes, J. (2007). Socioemotional Wealth and Business Risks in Family-controlled Firms: Evidence from Spanish Olive Oil Mills. Administrative Science Quarterly, 52(1), 106-137. https://doi.org/10.2189/asqu.52.1.106

Groves, K. S. (2018). Succession Management Capabilities: Planning for the Inevitable Transition of Executive Talent. Academy of Management Proceedings, 2018(1), 15773. https://doi.org/10.5465/AMBPP.2018.15773abstract

Guerini, A. G. \& Mattje, C. de O. (2018). Os benefícios da formalição de uma holding familiar. Trabalho de Conclusão de Curso (Bacharel Ciências Contábeis). Centro Universitário Dinâmica das Cataratas-UDC, Foz do Iguaçu.https://semanaacademica.org.br/system/files/artigos/tcc_2_0.pdf

Kellermanns, F. W., Dibrell, C., \& Cruz, C. (2014). The role and impact of emotions in family business strategy: new approaches and paradigms. Journal of Family Business Strategy, 5(3), 277-279.

Hall, D. T. (1986). Dilemmas in linking succession planning to individual executive learning. Human Resource Management, 25(2), 235 -265.

Harrison, E. F. (1993). Interdisciplinary models of decision making. Management Decision.

Lodi, J. B. (1993). A Empresa Familiar. Pioneira.

Lodi, J. B. (1994). A Ética na Empresa Familiar. Pioneira

Maillard, N. de A. P. G. et al. (2020). Processo sucessório nas organizações públicas brasileiras. Tese (Doutor em Ciêncas). Universidade de São Paulo, São Paulo.

Mamede, C. A. da S., Melo, M. C. de O. L., \& Pinto, R. A. (2017). A visão empreendedora e o processo de sucessão em empresa familiar. Perspectivas Contemporâneas, 12(1), 169-187.

Martelli, A. et al. (2020). Análise de metodologias para execução de pesquisas tecnológicas. Brazilian Applied Science Review, 4(2), $468-477$.

Maximiano, A. C. A. (2016). Introdução à Administração. Atlas.

Medeiros, A. B. de, Costa-Nunes, S., Moyzes-Sarsur, A., \& Costa de Amorim, W.-A. (2019). Processo sucessório: O complexo desafio do desenvolvimento de lideranças. Estudios Gerenciales. https://doi.org/10.18046/j.estger.2019.151.3136 
Miranda, C. V. dos S. (2019). Os impactos da proximidade da morte do fundador na gestão de uma empresa familiar. Trabalho de conclusão de curso (barachel em administração). Universidade Federal de Uberlândia, Uberlândia, Brasil. https://repositorio.ufu.br/handle/123456789/27236

Muritiba, S. N., Muritiba, P. M., Domingues, L. M., Di Dio, G., \& Zavarizzi, F. (2016). governança corporativa e sucessão em empresas familiares. Revista de Carreiras e Pessoas, 6(3). https://doi.org/10.20503/recape.v6i3.31062

Lisboa, J., Coelho, A., Coelho, F., \& Almeida, F. (2004). Introdução à gestão de organizações. Barcelos: Vida Económica.

Ohtsuki, C. H. (2013). Como as organizações brasileiras identificam pessoas aptas a assumir atribuições e responsabilidades no contexto do processo sucessório: Um estudo de caso [Mestrado em Administração, Universidade de São Paulo]. https://doi.org/10.11606/D.12.2013.tde-26112013-203629

Oliveira, D. de P. R. (2000). Empresa Familiar: Como fortalecer o empreendimento e otimizar o processo sucessório. Atlas.

Oro, I. M., \& Facin Lavarda, C. E. (2017). Interaction between strategy and organizational performance: The influence of family management. BBR. Brazilian Business Review, 14, 493-509.

Piccoli, E. R., Matte, J., Chais, C., Ganzer, P. P., Miri, D. H., \& Olea, P. M. (2019). empresas familiares: um estudo sobre sucessão e continuidade. Revista Brasileira de Estudos Organizacionais, 6(1), 237-268. https://doi.org/10.21583/2447-4851.rbeo.2019.v6n1.152

Ricca, D. (1998). Da empresa familiar à empresa profissional. CL- A Cultural.

Robertsson, H.; Zellweger, T. \& Hsueh, J. W-J. (2021). How the world's largest family businesses are proving their resilience. https://familybusinessindex.com.

Rodrigues, J. (2019). Liderança e Sucessão em contexto de Empresas Familiares. ISLA Multidisciplinary e-Journal, 2(1), 16-32.

Rosa, H. C. (2019). A sucessão na empresa familiar: um estudo de caso na empresa polo sul logística. Repositório de Trabalhos de Conclusão de Curso. http://pensaracademico.unifacig.edu.br/index.php/repositoriotcc/article/view/895

Ruffatto, J., Pauli, J., \& Ferrão, A. R. (2017). Influência do estilo de liderança na motivação e conflitos interpessoais em empresas familiares. Revista de Administração FACES Journal. https://doi.org/10.21714/1984-6975FACES2017V16N1ART3616

Santos, T. R., \& Silva, J. O. (2018). A influência da família tem algum efeito? Análise da remuneração dos executivos das empresas familiares e não familiares. Revista de Contabilidade e Organizações, 12, 1-12.

Schreiber, D., \& Froehlich, C. (2020). O processo de reposicionamento estratégico em uma empresa familiar do rio grande do sul. Revista Alcance, 27(1), 4762 .

Serviço Brasileiro de Apoio às Micro e Pequenas Empresas .SEBRAE. (2021a). Pais e filhos: os desafios e valores entre gerações de empreendedores https://www.sebrae.com.br/sites/PortalSebrae/ufs/ms/artigos/pais-e-filhos-os-desafios-e-valores-entre-geracoes-de-

empreendedores,f646cf80c782c710VgnVCM100000d701210aRCRD\#: :text=De\%20acordo\%20com\%20dados\%20do,Brasil\%20seguem\%20o\%20modelo\% 20familiar.

Serviço Brasileiro de Apoio às Micro e Pequenas Empresas .SEBRAE. (2021b). Guia completo sobre a gestão de empresas familiares. https://www.sebrae.com.br/Sebrae/Portal\%20Sebrae/Arquivos/Guia\%20sobre\%20gesta\%CC\%83o\%20de\%20empresas\%20familiares.pdf .

Silva, C. R. da, Cruz, A. P. C. da, Barbosa, M. A. G., \& Machado, D. G. (2017). Uso do Sistema de Controle Gerencial como Instrumento de Implementação da Estratégia_O Caso de uma Empresa Familiar. Revista Contabilidade e Controladoria, 9(3). https://doi.org/10.5380/rcc.v9i3.53872

Silva, R. (2014). Processo sucessório na governança de organizações familiares: um estudo exploratório nas "Mehores Empresas. Revista de Carreiras e Pessoas (ReCaPe)|ISSN-e: 2237-1427, 4(1). https://doi.org/10.20503/recape.v4i1.19416

Silva, R. (2018). Estudos qualitativos: enfoques teóricos e técnicas de coleta de informações (Orgs). Sobral: edições UVA.

Simon, H. A. (1965). Comportamento administrativo: estudo dos processos decisórios nas organizações administrativas. Fundação Getúlio Vargas.

SOUZA, J. (2002). Gestão de empresa familiar: refletindo sobre suas peculiaridades e desafios. Salvador: FTE.

Teston, S. de F \& Filippim, E. S. (2016). Perspectivas e desafios da preparação de sucessores para empresas familiares. Revista de Administração Contemporânea, 20,524-545.

Tillmann, C., \& Grzybovski, D. (2005). Sucessão de dirigentes na empresa familiar: estratégias observadas na família empresária. Organizações \& Sociedade, 12, 45-61.

Triviños, A. N. S. (1987). Introdução à pesquisa em ciências sociais: a pesquisa qualitativa em educação. Atlas.

Troccoli, I. R., \& Lisboa, F. (2018). Governança corporativa na empresa familiar. Revista Vianna Sapiens, 9(1), 32-32.

Vieira, A. C. P., Maccari, G. M., Freire, P. de S., Zilli, J. C. F., \& Topanotti, A. P. (2014, dezembro 3). Análise de Modelos de Tomada de Decisão para Implantação em Empresas Familiares a Fim de Evitar Conflitos e Interferências. XIV Mostra de Iniciação Científica, Pós-graduação, Pesquisa e Extensão.
XIV
de Iniciação
Científica,
Pós-graduação,
Pesquisa
Extensão.

http://www.ucs.br/etc/conferencias/index.php/mostraucsppga/mostrappga2014/paper/view/3764

Vinagre, L. M., Silva, S. W., Júnior, P. D. S. P., da Silva Souza, R., Gonçalves, J. E., \& PEREIRA, W. F. (2017). O processo sucessório em uma empresa familiar: um estudo de caso em um supermercado de Varginha-MG. Revista da Universidade Vale do Rio Verde, 15(1), 689-700

Vogt, M.; Haveroth, J.\& Zonatto, V. C. da S. (2017). Efeito das Emoções na Tomada de Decisão Estratégica de uma Empresa Familiar de Santa Catarina. https://congressousp.fipecafi.org/anais/17UspInternational/ArtigosDownload/539.pdf 